\title{
Analysis of chlorophyll fluorescence reveals stage specific patterns of chloroplast-containing cells during Arabidopsis embryogenesis
}

\author{
RICARDO I. TEJOS ${ }^{1,2, \#, \text { ANA V. MERCADO }}{ }^{2,3, \#}$ and LEE A MEISEL ${ }^{1,2, *}$ \\ ${ }^{1}$ Centro de Biotecnología Vegetal, Facultad de Ciencias Biológicas, Universidad Andres Bello, Santiago, \\ Chile \\ ${ }^{2}$ Millennium Nucleus in Plant Cell Biotechnology (MN-PCB), Santiago, Chile \\ ${ }^{3}$ Departamento de Acuicultura. Universidad de Antofagasta, Antofagasta. Chile \\ \# these authors contributed equally to this work
}

\begin{abstract}
The basic body plan of a plant is established early in embryogenesis when cells differentiate, giving rise to the apical and basal regions of the embryo. Using chlorophyll fluorescence as a marker for chloroplasts, we have detected specific patterns of chloroplast-containing cells at specific stages of embryogenesis. Nonrandomly distributed chloroplast-containing cells are seen as early as the globular stage of embryogenesis in Arabidopsis. In the heart stage of embryogenesis, chloroplast containing cells are detected in epidermal cells as well as a central region of the heart stage embryo, forming a triangular septum of chloroplast-containing cells that divides the embryo into three equal sectors. Torpedo stage embryos have chloroplast-containing epidermal cells and a central band of chloroplast-containing cells in the cortex layer, just below the shoot apical meristem. In the walking-stick stage of embryogenesis, chloroplasts are present in the epidermal, cortex and endodermal cells. The chloroplasts appear reduced or absent from the provascular and columella cells of walking-stick stage embryos. These results suggest that there is a tight regulation of plastid differentiation during embryogenesis that generates specific patterns of chloroplast-containing cells in specific cell layers at specific stages of embryogenesis.
\end{abstract}

Key terms: chloroplast, plastid differentiation, embryogenesis.

Abbreviations: ABRC, Arabidopsis Biological Resource Center; Em, emissions; Ex, excitation; NEP, Nuclear encoded RNA polymerase; PEP, Plastid encoded RNA polymerase.

\section{INTRODUCTION}

During embryonic development cells differentiate by a coordinated process of changes in gene expression that subsequently lead to changes in the types and levels of proteins, as well as alterations in cellular structure. In addition to these changes, the organelles in cells may also differentiate with the differentiation of their host cell. Among the organelles in differentiating cells, plastids develop from pre-existing proplastids or other plastid types, to generate a great diversity in plastid shape and function, each intimately linked to its host-cell developmental state and functionality (Lopez-Juez and Pyke, 2005; Pyke, 1999). For example, during the first stages of Arabidopsis leaf formation, the plastids appear undifferentiated. However, during leaf development they differentiate inside mesophyll and parenchyma cells, generating completely developed chloroplasts with a characteristic internal membranous system with starch, protein and/or lipid accumulations (Lopez-Juez and

\footnotetext{
* Corresponding author: Lee A Meisel, Centro de Biotecnología Vegetal, Facultad de Ciencias Biológica, Universidad Andrés Bello, Av. República 217, 837-0146, Santiago, Chile, Phone: 56-2-661-8449, Fax: 56-2-661-5832, Email: lmeisel@gmail.com
} 
Pyke, 2005). Additionally, in the leaf epidermis of Arabidopsis, only leaf guard mother cells and guard cells contain fully developed chloroplasts, whereas other epidermal cells do not (Zhao and Sack, 1999). Another example is the differentiation of chloroplast to leucoplast in the Arabidopsis petal cells, from petal stalk chloroplast-containing cells to the upper white petal lamina with leucoplastcontaining cells (Pyke and Page, 1998). Plastid differentiation to amyloplasts in columella cells has also been well described. In these cells, there is a progressive accumulation of apparently non-polarized starch containing organelles to the formation of basally-located amyloplasts (Blancaflor et al., 1998; Rosen et al., 1999; Van Den Berg et al., 1997; Wildwater et al., 2005).

Mature chloroplasts contain a large number of different proteins. Some of these proteins are encoded in the plastid genome, however the majority (>95\%) are encoded by nuclear genes (Lopez-Juez, 2007). The interaction between these two spatially separated genomes must be finely regulated in order for proper chloroplast biogenesis and function to occur. This interaction includes nucleus to plastid (anterograde signaling) and plastid to nucleus (retrograde signaling) (Woodson and Chory, 2008). During early phases of chloroplast biogenesis, the nucleus transcribes important chloroplast genes using nuclear encoded RNA polymerase (NEP), which "switches on" the transcriptional machinery in the plastid, allowing the expression of "housekeeping genes" important for the priming of the plastid. Later in the differentiation process, a plastid encoded $R N A$ polymerase (PEP) is more active and transcribes photosynthesis-related genes (Hajdukiewicz et al., 1997; Maliga, 1998; Santis-Maciossek et al., 1999; Woodson and Chory, 2008). These results suggest that the switch from NEP activity to PEP activity is important for developmental changes.

The nucleus controls the spatial-temporal specificity of plastid transcription by regulating nuclear encoded sigma factors that, in turn, regulate the specificity of PEP activity (Kanamaru and Tanaka, 2004; Woodson and Chory, 2008). Additionally, the chloroplast is constantly sending signals to the nucleus to inform it about the state of the chloroplast, such that postdevelopmental processes may be regulated (i.e. adaptation to light intensity and photobleaching, chloroplast biogenesis during leaf formation) (Nott et al., 2006). This retrograde signaling includes chlorophyll derived molecules, reactive oxygen species and redox signaling that regulate the transcriptional status in the organelle through nuclear encoded factors, such as the genomes uncoupled, (GUN), abscisic acid insensitive 4 (ABI4) and EXECUTER1, -2 (Woodson and Chory, 2008).

It is widely accepted that there is nuclear control of many aspects of chloroplast biogenesis (Leon et al., 1998). Several mutants in nuclear genes have impaired chloroplast transcription and translation (Gutierrez-Nava et al., 2004; Mandel et al., 1996; Pfalz et al., 2006), protein assembly and import into the organelle (Constan et al., 2004; Kubis et al., 2004; Sundberg et al., 1997), chloroplast division (Aldridge et al., 2005; Pyke, 1999), response to external stimulus such as the light (Chun et al., 2001) and communication between the chloroplast and nucleus (Larkin et al., 2003; Mochizuki et al., 2001). Interestingly, many of these genes produce aberrations in chloroplast biogenesis due to an incorrect accumulation/ assembly of photosynthetic proteins, producing colorless proplastid-like chloroplasts. In the more severe cases, embryo development is arrested prior to the globular stage of embryogenesis. These embryonically lethal nuclear mutants, with altered chloroplast biogenesis, affect the early stages of chloroplast development prior to the accumulation of the photosynthetic genes and thylakoid formation (Apuya et al., 2002; Hormann et al., 2004; Kubis et al., 2004; Lopez-Juez, 2007; Uwer et al., 1998; $\mathrm{Xu}$ and Moller, 2004; Yu et al., 2004). This strongly suggest that chloroplast function is necessary for proper Arabidopsis embryogenesis (Lopez-Juez, 2007). Despite our knowledge of chloroplast division (Aldridge et al., 2005), chloroplast biogenesis (Aluru et al., 2006) and chloroplast-to-nucleus (Nott et al., 2006) or 
nucleus-to-chloroplast signaling (Leon et al., 1998; Somanchi and Mayfield, 1999), very little is known about the embryonic origin of chloroplasts. It is unclear whether chloroplasts are necessary for proper embryo development and whether there are specific patterns of chloroplast-containing cells during specific stages of embryogenesis.

Although it has been reported previously that chloroplasts are present in the late stages of Arabidopsis embryogenesis (Apuya et al., 2002; Apuya et al., 2001; GutierrezNava et al., 2004) and that chlorophyll fluorescence is widely used as a background marker in embryo imaging, to our knowledge a detailed description of the embryonic stages and cell types that contain chloroplasts have not been reported previously. In order to determine if stage specific patterns of chloroplast-containing cells are present during Arabidopsis embryogenesis, we have quantified chlorophyll fluorescence as a marker for plastids that have differentiated into chloroplasts. Using this marker, we demonstrate that reproducible stage-specific patterns of chlorophyll are detected in embryos at the globular, heart, torpedo and walking-stick stages of embryogenesis. These results suggest that there is a tight regulation of plastid-to-chloroplast differentiation in specific cells and at specific stages of embryogenesis. Additionally, these results demonstrate that the quantification of chlorophyll fluorescence may be used as a marker for differentiated cells that contain chloroplasts early in Arabidopsis embryogenesis. The reproducible patterns of chloroplastcontaining cells presented in this paper will serve as a reference map for future analyses of mutants that may alter these patterns as well as the body plan that is established during embryogenesis.

\section{METHODS}

\section{Plant material and growth conditions}

Wild type Col-0 plants were grow at $22^{\circ} \mathrm{C}$ with a $16 \mathrm{~h}$ light, $8 \mathrm{~h}$ dark cycle, $120 \mu \mathrm{mol}$ m-2 s-1 cool white light. Embryos were dissected from immature siliques at three, five, six, nine and 12 days post-anthesis. Under our growth conditions, globular stage embryos were observed at three days post-anthesis, heart stage embryos at five days post-anthesis, torpedo stage embryos at six days post-anthesis and walking-stick stage embryos at nine days post-anthesis. A minimum of three embryos were analyzed at each stage of embryogenesis.

\section{Chloroplast detection using confocal microscopy}

Walking stick and torpedo stage embryos were obtained by dissecting the silique with two needles under a dissecting microscope and mounting the embryos in slides containing $0.5 \mathrm{X} \mathrm{MS}$ and $50 \%$ glycerol. Earlier stage embryos were mounted in the same solution and squashed using the point of a pencil. Since maternal tissue interferes with the detection of the fluorescence in the embryos, embryos that had been separated from the maternal tissue were selected for further analyses. Immediately following dissection, the mounted embryos were stored in the dark until the autofluorescence in these embryos was visualized using a Zeiss LSM510 Meta Confocal Microscope with a $488 \mathrm{~nm}$ excitation laser, dichroic filter HFT514/633 and emission filter LP650. An emission wavelength spectrum (601-783 nm) was performed on walkingstick stage embryos and leaves from wildtype Arabidopsis. The peak emissions fluorescence wavelength $(687 \mathrm{~nm})$ determined in this spectrum analysis was used for all subsequent analyses. Optical sections were made of each sample by detecting the first plane of fluorescence and performing serial sections until fluorescence was no longer detected. Sections were performed every $2.2 \mu \mathrm{m}$ in the globular stage, $3.3 \mu \mathrm{m}$ in the heart stage, $4.3 \mu \mathrm{m}$ in the torpedo stage and 5.0 $\mu \mathrm{m}$ in the walking stick stage embryo.

\section{Fluorescence quantification}

The intensity of chlorophyll fluorescence was quantified with the LSM510 Meta Confocal professional software using 
optical sections located in the center of each embryo. A more precise quantification of the fluorescence at each stage of embryogenesis was determined by quantifying the fluorescence within transects of the midsections of at least three embryos at each stage of embryogenesis. Two transects were analyzed in the globular stage embryos, three transects were analyzed in the heart, torpedo and walkingstick stages of embryogenesis. Midsection transects of globular stage embryos were performed at $1 / 3$ and $2 / 3$ of the maximum width of the embryo, perpendicular to the putative suspensor anchoring site. Midsection transects of globular and torpedo stage embryos were performed within the region of the shoot apical meristem, within the region of the root apical meristem and within the protoderm indention zone (Scheres et al., 1994). In walking-stick stage cotyledons, midsection transects were performed in the center of one of the cotyledons (perpendicular to the mid-vein), within the region of the root apical meristem and the region equidistant from the shoot and root meristems (perpendicular to the central axis of the embryo). In all cases, the fluorescence was plotted as the relative fluorescence (I) versus the relative distance of each point (X) as follows:

$I=\frac{I i-\operatorname{Min}(\operatorname{In})}{\operatorname{Max}(\operatorname{In})} \quad X=\frac{X i}{\operatorname{Max}(X n)}$

where Ii is the fluorescence of each point, and $\operatorname{Min}(\mathrm{In})$ and $\operatorname{Max}(\mathrm{In})$ are the minimum and maximum fluorescence point in each sample, and $\mathrm{Xi}$ is the distance of each point relative to the border of the embryo and $\operatorname{Max}(\mathrm{Xn})$ is the length of the transect.

\section{Transmission Electron Microscopy}

Walking-stick stage embryos were fixed for $24 \mathrm{~h}$ at room temperature in a solution containing $3 \%$ glutaraldehyde and $4 \%$ paraformaldehyde in a $0.1 \mathrm{M}$ cacodylate buffer, $\mathrm{pH}$ 7.2. Samples were washed with $0.1 \mathrm{M}$ cacodylate buffer, $\mathrm{pH} 7.2$ and treated for $3 \mathrm{~h}$ in $1 \%$ OsO4 in the same buffer. Samples were subsequently dehydrated, embedded in Epon Resin and cut into $1 \mu \mathrm{m}$ ultra-fine longitudinal sections. Sections were stained for $30 \mathrm{~min}$ with Uranyle acetate and lead citrate, and visualized in a Philips Electron Microscope at $60 \mathrm{kV}$ (Saether and Iversen, 1991).

\section{RESULTS}

Optical sectioning of Arabidopsis embryos using confocal microscopy reveals stage specific patterns of chlorophyll fluorescence during Arabidopsis embryogenesis

Chlorophyll fluorescence was analyzed in Arabidopsis embryos at the globular, heart, torpedo and walking-stick stages of embryogenesis by optically sectioning the embryos using a confocal microscope (Fig. 1 and 2). Foci of chlorophyll fluorescence were observed in all stages of embryogenesis analyzed, suggesting that the chlorophyll fluorescence is localized in individual chloroplasts. A summary of chlorophyll fluorescence patterns at specific stages of embryogenesis and the intensity of chlorophyll fluorescence within the midsection of the embryos are shown in Fig. 1. Optical sections of representative embryos appear in Fig. 2. To confirm the reproducibility of these fluorescent patterns, the intensity of chlorophyll fluorescence was quantified in midsection transects of three embryos at each stage of embryogenesis (Fig. 3 and 4).

Specific patterns of chlorophyll fluorescence were observed for each stage of embryogenesis analyzed (Fig. 1-4). Nonrandom chlorophyll fluorescence was detected in the protodermal cells and ground tissue of globular stage embryos (Fig. 1A-B; 2A-G; 3A; $4 \mathbf{A}-\mathbf{C}$ ). A small region of the protodermal cell layer of globular stage embryos, near the suspensor, lacked fluorescence. In the heart stage of embryogenesis, chlorophyll fluorescence was observed in the epidermis as well as a few cells within the central region of the embryo (Fig. 1C-D; 2H-N; 3B, central fluorescence peak is detected in transect $\mathrm{d}$ of Fig. 3B; Fig. 4D-F). This fluorescence forms a triangular septum pattern (indicated 

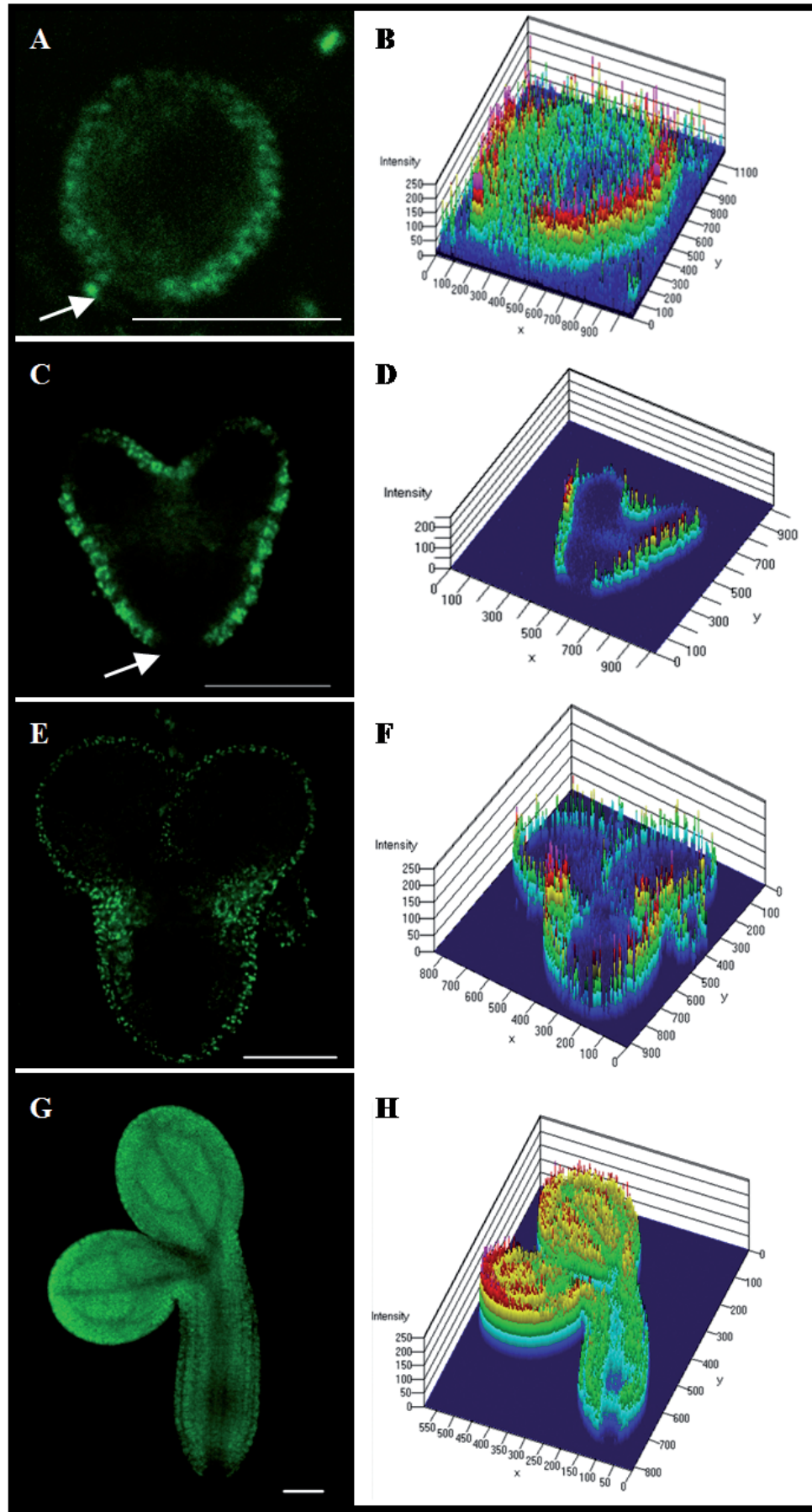

$\mathbf{H}$

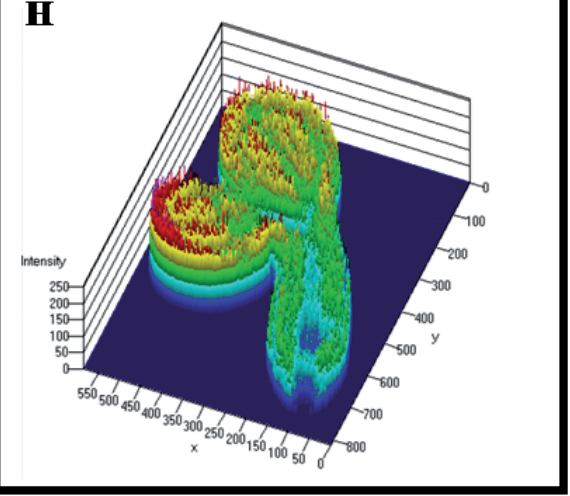

Figure 1: Specific patterns of chlorophyll fluorescence are present in specific stages of Arabidopsis embryogenesis.

Arabidopsis embryos at the globular (A-B), heart (C-D), torpedo (E-F), and walking-stick (G-H) stages of embryogenesis were analyzed for chlorophyll fluorescence using confocal microscopy (Ex $488 \mathrm{~nm}, \mathrm{Em} 687 \mathrm{~nm}$ ). Chlorophyll fluorescence detected in optical midsections of embryos at specific stages of embryogenesis (A, C, E, G). The fluorescence in the midsection was quantified to show the pattern and intensity of fluorescence $(\mathrm{B}, \mathrm{D}, \mathrm{F}, \mathrm{H})$. Red represents the maximum fluorescence and blue the minimum. The arrows in $\mathrm{A}$ and $\mathrm{C}$ mark the protodermal cell layer, near the suspensor, lacking fluorescence. The bars in the figures represent $50 \mu \mathrm{m}$. 
by the arrows in Fig. 2J-L) that separates the heart stage embryo into three sectors: two apical sectors corresponding to future cotyledons and a basal sector corresponding to the root apex. Within the core region of each of these sectors, there was a reduction or absence of chlorophyll fluorescence (Fig. 3B; Fig. 4D-F). These three sectors are still present in the torpedo stage, where the chlorophyll fluorescence was again apparent in the epidermal cell layer (Fig. 1E-F; Fig. 2O-U; Fig. 3C; Fig. 4G-I). However, a specific band of fluorescence was also observed in the juncture, just below the shoot apical meristem near the base of the cotyledons (indicated by the arrow in Fig. $\mathbf{2 R}$ ). This band of fluorescence appears in the epidermal and cortex layers of the embryo. Chlorophyll fluorescence is readily detectable in the epidermis, cortex and endodermis of walking-stick stage embryos (Fig. 1G-H; Fig. 2V-Ab; Fig. 3D; Fig. 4JL). However, there is an absence or a reduction in chlorophyll fluorescence in the provascular cell layer and the central columella region of the root apex (indicated by the arrow in Fig. 2Y).

Little or no fluorescence was detected in the suspensor cells in all stages of embryogenesis analyzed (data not shown). In the heart stage embryo, the apical cells of the suspensor (the hypophysis), also did not contain detectable levels of fluorescence (Fig. 1C-D; Fig. 2H-N; Fig.
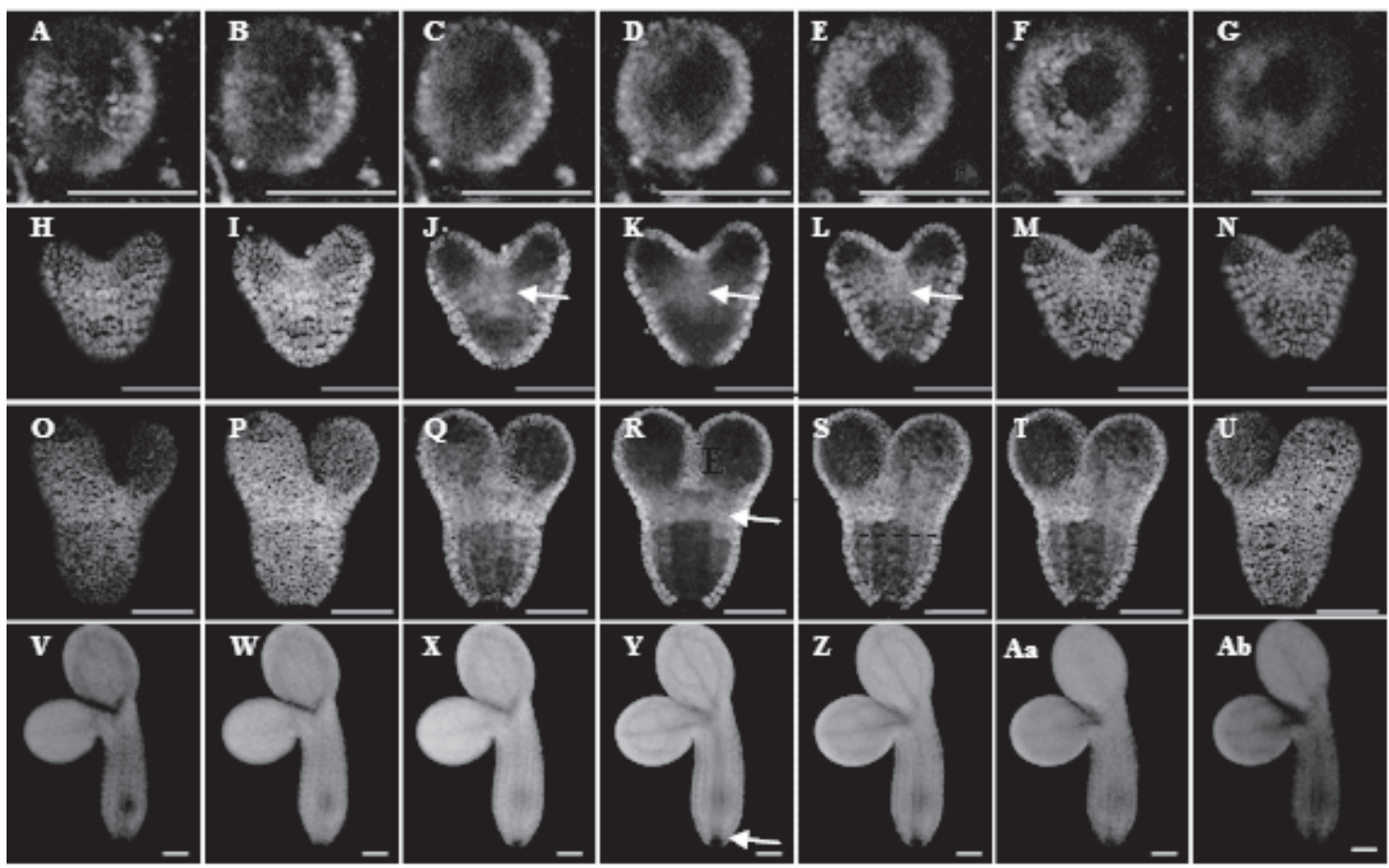

Figure 2: Serial optical sections of chlorophyll fluorescence in Arabidopsis reveal specific patterns of chloroplast-containing cells at specific stages of embryogenesis.

Arabidopsis embryos at the globular $(\mathrm{A}-\mathrm{G})$, heart $(\mathrm{H}-\mathrm{N})$, torpedo $(\mathrm{O}-\mathrm{U})$, and walking-stick $(\mathrm{V}-\mathrm{Ab})$ stages of embryogenesis were analyzed for chlorophyll fluorescence using confocal microscopy (Ex $488 \mathrm{~nm}$, Em $687 \mathrm{~nm}$ ). Optical sections were taken every $2.2 \mu \mathrm{m}$ in globular; $3.3 \mu \mathrm{m}$ in heart; 4.3 $\mu \mathrm{m}$ in torpedo; and $5.0 \mu \mathrm{m}$ in walking-stick stages. Optical sections showing chlorophyll fluorescence in the midsection of the embryos at specific stages of embryogenesis are seen in D, K, $\mathrm{R}$ and $\mathrm{Y}$. The arrows in $\mathrm{J}-\mathrm{L}$ depict the triangular septum of chlorophyll fluorescence. The arrow in $\mathrm{R}$ depicts the band of chlorophyll fluorescence in the region just below the shoot apical meristem near the base of the future cotyledons. In Y, the arrow depicts the region of reduced fluorescence at the root apex and the region distal to the root apex. Bar in all figures represents $50 \mu \mathrm{m}$. 
3B; Fig. 4D-F). These cells give rise to the root apex, including the root meristem (Scheres et al., 1994; Weijers et al., 2006). In the torpedo and walking stick stages of embryogenesis, detectable levels of chlorophyll fluorescence are not seen in the columella cells. However, the lateral root cap cells have chloroplasts (Fig. 5).

Chloroplasts are present in specific cells in mature Arabidopsis embryos

Further supporting evidence for the presence of chloroplasts in specific cells in the mature embryo of Arabidopsis was obtained using transmission electron microscopy (Fig. 5). As was seen in the optical confocal microscopy sections, walking-stick stage embryos contain chloroplasts in epidermal and cortex cells in the cotyledons and hypocotyl (Fig. 5B and C, respectively). These chloroplasts are easily identified due to the presence of internal thylakoid membranes. Chloroplasts are also present in endodermal and cortex cell layers in the walking-stick stage embryonic root (Fig. 5D-H). The cortex initial contains less developed chloroplasts
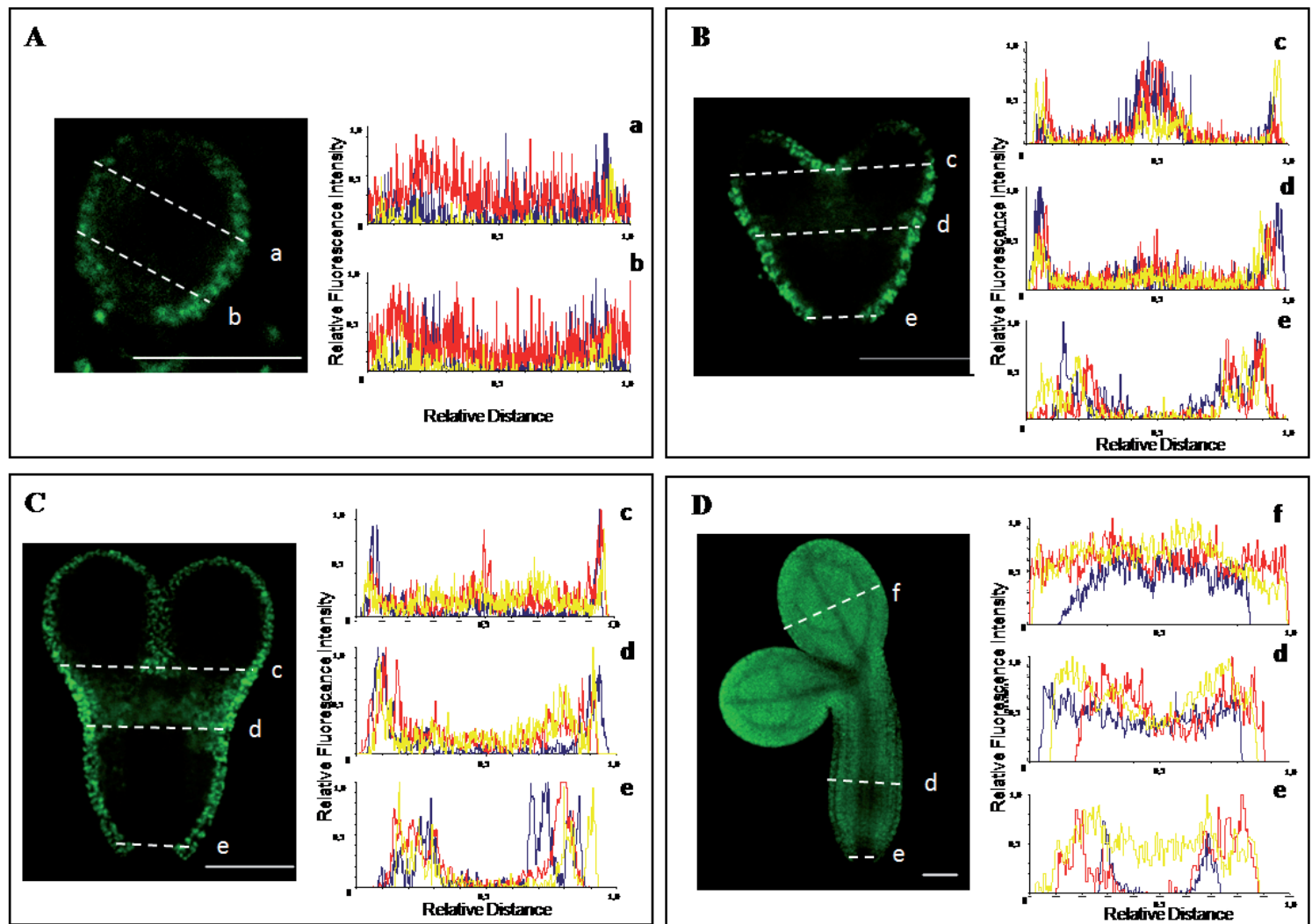

Figure 3: Chlorophyll intensity profile analyses of embryo midsections at different stages of embryogenesis reveal specific patterns of chloroplast-containing cells for specific stages of embryogenesis.

Optical midsections of three embryos were analyzed for chlorophyll fluorescence intensity at each stage of embryogenesis. The chlorophyll intensity was quantified across arbitrarily assigned transects of these midsections in the globular stage embryos (a and b), as well as in the apices (c and e) and the indention zone (d) in the heart (B), torpedo (C) and walking stick (D) stages of embryogenesis. An additional transect was analyzed in the middle of the cotyledon (f) in the walking stick embryos. Details of the calculations used to determine relative fluorescence intensities are explained in the Materials and Methods section of this paper. The different colors in the "Relative Fluorescence Intensity" graphs represent three different embryos that were quantified. 

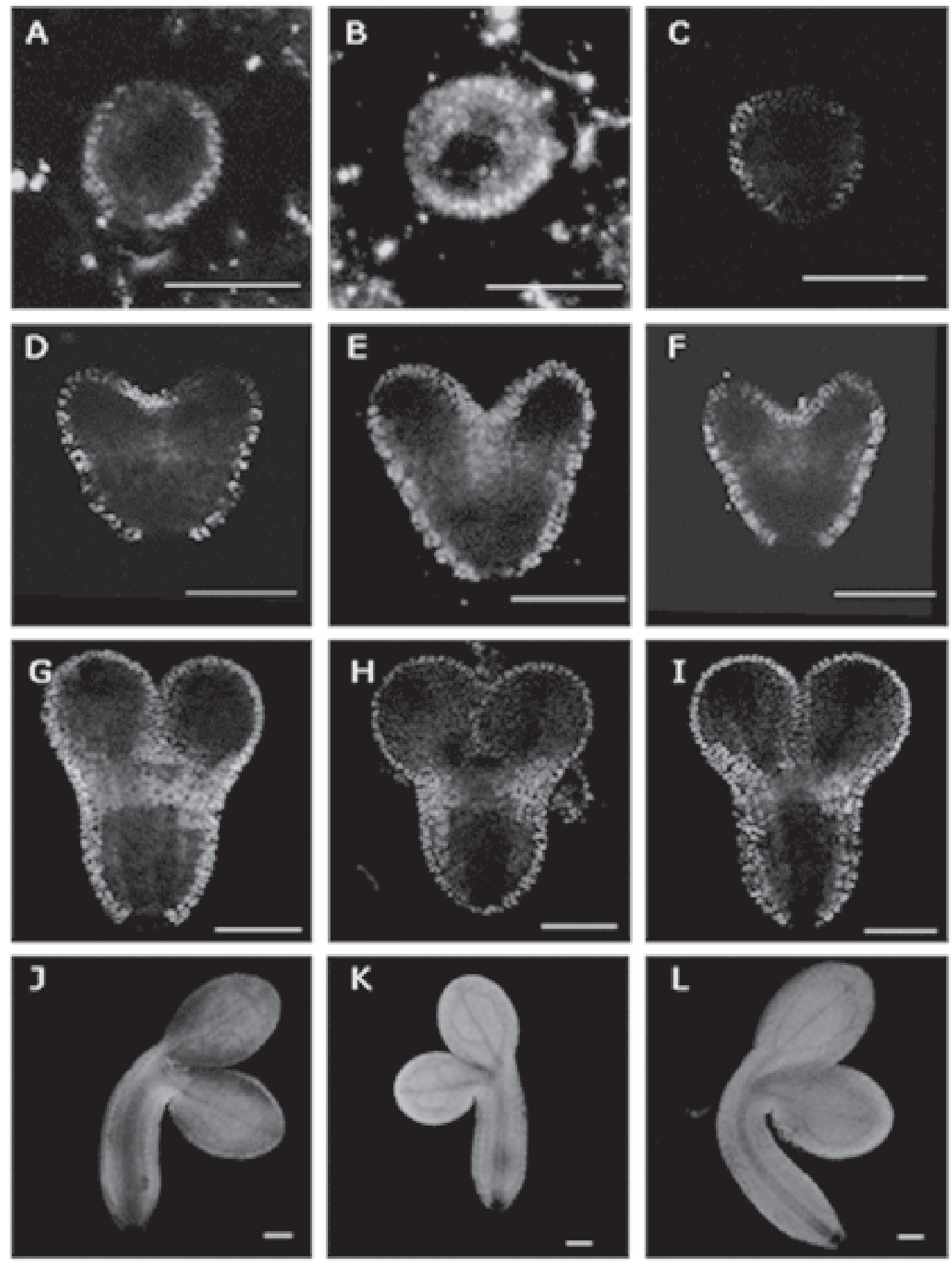

Figure 4: Three independent embryos at the globular, heart, torpedo and walking-stick stages of Arabidopsis embryogenesis reveal specific patterns of non-random chlorophyll fluorescence at specific stages of Arabidopsis embryogenesis.

The embryos in globular (A-C), heart (D-F), torpedo $(\mathrm{G}-\mathrm{H})$ and walking stick stages (J-L) were dissected from distinct siliques and visualized under the same conditions. Central optical sections of each embryo are shown. The bar indicates $50 \mathrm{~mm}$. 

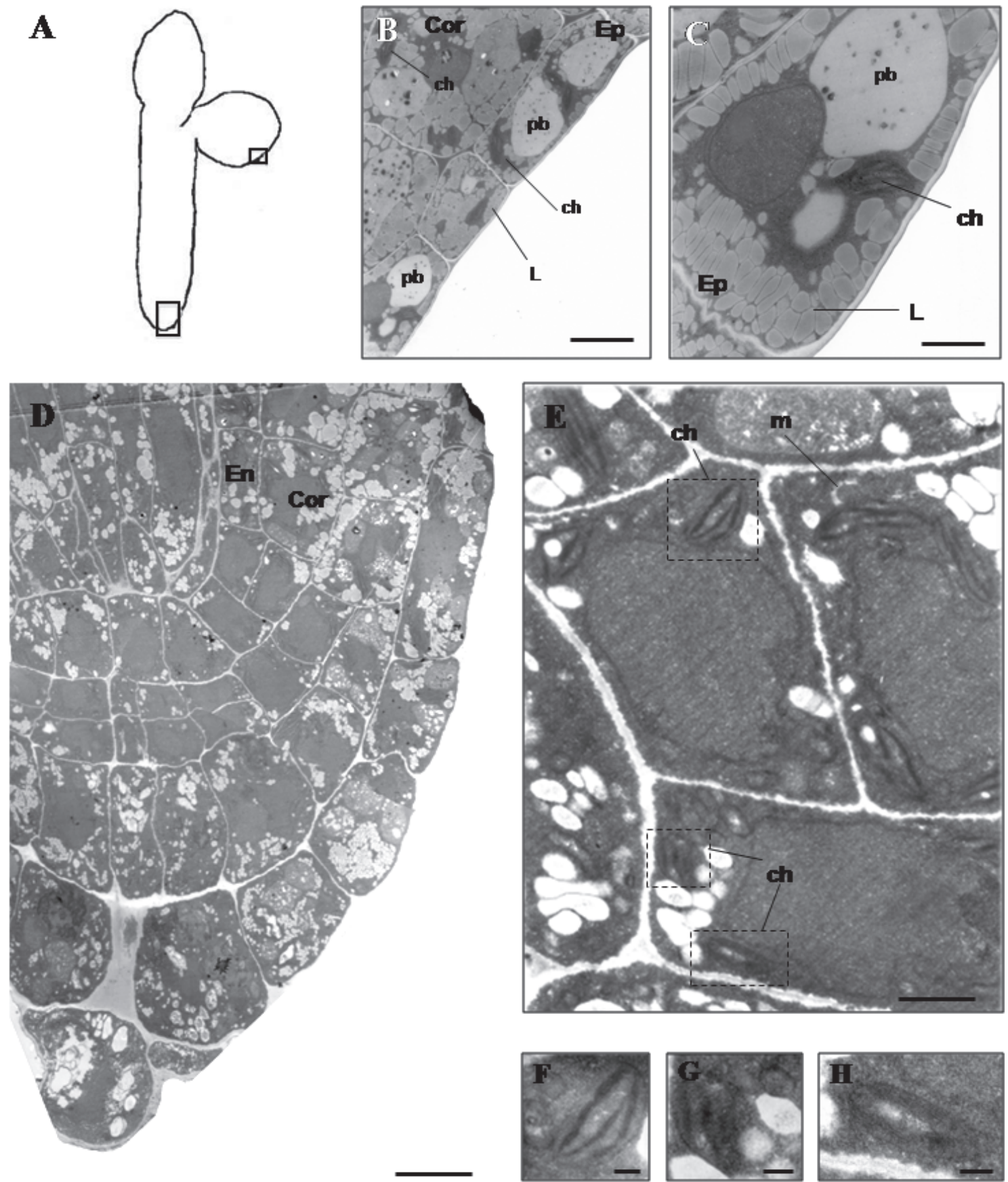

Figure 5: Transmission electron microscopy confirms the presence of differentiated chloroplasts in specific cells in the mature Arabidopsis embryo.

A schematic representation of a walking-stick stage embryo (A), the boxed regions in this drawing represent the regions that are shown in detail in B-D: epidermal and cortex cell layers of the embryonic cotyledon (B); epidermal cell (C); root apex (D). Root apex containing the cortex initial (lower cell), the cortex (cell on the right, above the cortex initial) and endodermal cells (cell on the left, above the cortex initial (E). Magnification of chloroplasts marked with the boxes in the endodermal cell (F) and the cortex initial $(\mathrm{G}-\mathrm{H})$. Cor: cortex; ep: epidermis, en: endodermis, ch: chloroplast; pb: protein body; L: lipid body; m: mitochondria. Bar represents $5 \mu \mathrm{m}$ in $\mathrm{B}$, C, and E; $10 \mu \mathrm{m}$ in $\mathrm{D}, 3.3 \mu \mathrm{m}$ in $\mathrm{F}-\mathrm{H}$. 
when compared to more differentiated cells (Fig. 5E-H, compare 5F with $5 \mathrm{G}$ and $5 \mathrm{H}$ ). Similar to what was observed with confocal microscopy, chloroplasts were not detected in the central columella cells nor in the provascular cells (Fig. 5D).

\section{DISCUSSION}

By quantifying chlorophyll fluorescence we have been able to demonstrate that this fluorescence may be used to detect chloroplast-containing cells that have specific patterns in specific stages of embryogenesis. A non-random distribution of chloroplast-containing cells was seen as early as the globular stage of embryogenesis (Fig. 1A-B). The distribution of the chloroplast-containing cells is different among globular, heart, torpedo and walkingstick stages of embryogenesis (Fig. 1). The specific patterns of chlorophyll fluorescence in specific stages of embryogenesis suggest that chloroplast differentiation may be used as a marker for cell differentiation during embryogenesis.

Our results suggest that embryonic and post-embryonic factors are involved in determining the ability of cells to contain chloroplasts. Anterograde and retrograde signals between the nucleus and plastids have been demonstrated to participate in chloroplast biogenesis during early stages of embryogenesis (Woodson and Chory, 2008). Mutations in nuclear-encoded genes for chloroplast localized proteins are often embryonically lethal (Apuya et al., 2002; Hormann et al., 2004; Kubis et al., 2004; Lopez-Juez, 2007; Uwer et al., 1998; Xu and Moller, 2004; Yu et al., 2004). Additionally, TargetP predictions of 220 $E M B$ genes, required for normal Arabidopsis embryo development, suggest that $32 \%$ of these genes are directed to chloroplasts (Tzafrir et al., 2004). Analyses of these $E M B$ genes has led to the proposal that a complete loss of critical chloroplast function in Arabidopsis results in embryo lethality, whereas partial loss of these functions or complete loss of peripheral functions result in defects after germination (Tzafrir et al., 2004).
Transcriptional profiling of the Arabidopsis embryo has revealed that during the transition from the globular to heart stage of embryogenesis, as well as the transition from the heart stage to torpedo stage, there is a significantly increased expression of genes involved in energy production, many of which are associated with the photosystem (Spencer et al., 2007).

As mentioned earlier, we were able to detect specific patterns of chloroplastcontaining cells in specific stages of embryogenesis. Specific patterns of chlorophyll fluorescence were detected in the protodermal cells and ground tissues of the globular stage embryo, but were not detected in a small region of the protoderm, near the suspensor (Fig. 1A-B; 2A-G; 3A; 4A-C).

As predicted by the transcript profile analyses (Spencer et al., 2007), the amount of chlorophyll fluorescence increased in the heart stage embryos and a distinct pattern of chloroplast-containing cells is seen. This pattern of chloroplast-containing cells is specific for the heart-stage embryo, dividing the embryo into three sectors (two apical sectors that will develop into cotyledons and a basal sector that will develop into the root apex) of chloroplastcontaining cell layers with an internal core that lacks chlorophyll fluorescence (Fig. 1C-D; 2H-N; 3B; Fig. 4D-F).

Once again, as predicted by the transcription profile analyses (Spencer et al., 2007), the chlorophyll fluorescence increased in the torpedo stage embryo. The pattern of chloroplast-containing cells detected in the heart stage is conserved in the torpedo stage, with the exception of a specific band of fluorescence in the epidermal and cortex cell layers in the region just below the shoot apical meristem (Fig. 1E-F; Fig. 2O-U; Fig. 3C; Fig. 4G-I).

The transcriptional profile analyses revealed an increased expression of genes associated with photosynthesis and carbon fixation at every stage of embryogenesis, reaching the maximum level of expression in cotyledons of mature embryos (Spencer et al., 2007). The mature embryo (walkingstick stage) showed the highest level of chlorophyll fluorescence as well as the 
maximum number of chloroplast-containing cells. At this stage of embryogenesis, chloroplast-containing cells were detected in the epidermal, cortex, and endodermal cells of the hypocotyl region as well as the future root (Fig. 1G-H; Fig. 2D; Fig. 3D; Fig. 4). Chloroplasts appear reduced or absent from provascular and columella cells, but present in the future cortex and endodermal root cells (Fig. 5E), which do not contain chloroplasts in the adult plant. This data suggests that the factors specific for provascular and columella cells have differentiated these cells such that they do not contain chloroplasts or have a reduced number of chloroplasts, possibly producing other types of plastids such as amyloplasts. These observations suggest that embryonic factor(s) may be involved in determining the capacity of some cells to contain chloroplasts, whereas others may contain other forms of plastids such as amyloplasts or proplastids.

It is important to note that the cell types that contain chloroplasts during embryogenesis do not necessarily maintain these chloroplasts in the adult plant. Chloroplasts were detected in the epidermal cells of walking-stick stage embryos by both chlorophyll fluorescence and transmission electron microscopy (Fig. 1GH; Fig. 2D; Fig. 3D; Fig. 4; Fig. 5). With the exception of guard cells and guard mother cells, chloroplasts are normally not found in epidermal cells of germinated Arabidopsis seedlings (Zhao et al., 1999). This difference between chloroplastcontaining epidermal cells in embryos and non-chloroplast-containing epidermal cells in germinated seedlings suggests that there are post- embryonic factors that are involved in preventing these cells from containing chloroplasts.

What role are these chloroplastcontaining cells playing in pattern formation and cell differentiation during embryogenesis? This question is difficult to answer at this moment. However, information may be inferred from studies of other plants. Rolletschek et al. have shown in legume seeds that embryonic photosynthesis increases biosynthetic fluxes, probably by providing $\mathrm{O}_{2}$ and energy that is readily used for biosynthesis and respiration (Rolletschek et al., 2003). Additionally, an increase of chlorophyll within the embryo of the legumes is correlated to $\mathrm{O}_{2}$ concentrations under light conditions. Similarly, in oilseed rape seeds (Brassica napus), chlorophyll content is correlated to the photosynthesis-dependent $\mathrm{O}_{2}$ evolution (Eastmond et al., 1996). Additionally, Allen et al (Allen et al., 2009) have demonstrated that the developing soybeans receive low but significant levels of light that contribute to the generation of ATP, as well as alterations in several metabolic processes.

Based upon these works (Allen et al., 2009; Eastmond et al., 1996; Rolletschek et al., 2003), as well as transcriptional profiling (Spencer et al., 2007), it may be inferred that the differential patterns of chlorophyll fluorescence detected in specific stages of Arabidopsis embryogenesis may change the local levels of $\mathrm{O}_{2}$ and ATP that may be used for cell specific biosynthesis and respiration. Localized alterations of the metabolic status of these cells in a stage and cell-specific manner may help contribute to positional information that regulates the differentiation of the cells during embryogenesis. Identification of mutants in the specific patterns of chloroplast-containing cells may provide insight into the role that these embryonic chloroplasts play in cell differentiation and development.

\section{ACKNOWLEDGEMENTS}

We would like to thank Alejandro Munizaga for his technical assistance with the TEM analyses, Lorena Saragoni for her technical assistance with confocal microscopy analyses and Juan Fernandez for his help in improving the resolution of the TEM images. We would also like to thank Daniela Urbina and Herman Silva for their critical comments concerning this manuscript. This research was funded by research grants from the Fondo Nacional de Desarrollo Científico y Tecnológico (Fondecyt \#1000812), ICM P02-009-F and ICM P06-065-F. 


\section{REFERENCES}

ALDRIDGE, C, MAPLE, J, MOLLER, SG (2005) The molecular biology of plastid division in higher plants. $\mathrm{J}$ Exp Bot 56: 1061-1077.

ALURU, MR, YU, F, FU, A, RODERMEL, S (2006) Arabidopsis variegation mutants: new insights into chloroplast biogenesis. J Exp Bot 57: 1871-1881.

ALLEN, DK, OHLROGGE, JB, SHACHAR-HILL, Y (2009) The role of light in soybean seed filling metabolism. Plant J 58: 220-234.

APUYA, NR, YADEGARI, R, FISCHER, RL, HARADA, JJ, GOLDBERG, RB (2002) RASPBERRY3 gene encodes a novel protein important for embryo development. Plant Physiol 129: 691-705.

APUYA, NR, YADEGARI, R, FISCHER, RL, HARADA, JJ, ZIMMERMAN, JL, GOLDBERG, RB (2001) The Arabidopsis embryo mutant schlepperless has a defect in the chaperonin-60 alpha gene. Plant Physiol 126: 717-730

BLANCAFLOR, EB, FASANO, JM, GILROY, S (1998) Mapping the functional roles of cap cells in the response of Arabidopsis primary roots to gravity. Plant Physiol 116: 213-222.

CONSTAN, D, PATEL, R, KEEGSTRA, K, JARVIS, P (2004) An outer envelope membrane component of the plastid protein import apparatus plays an essential role in Arabidopsis. The Plant Journal 38: 93-106.

CHUN, L, KAWAKAMI, A, CHRISTOPHER, DA (2001) Phytochrome A mediates blue light and UV-Adependent chloroplast gene transcription in green leaves. Plant Physiol 125: 1957-1966.

EASTMOND, P, KOLÁCÁ, L, RAWSTHORNE, S (1996) Photosynthesis by developing embryos of oilseed rape (Brassica napus L.). J Exp Bot 47: 1763-1769.

GUTIERREZ-NAVA, ML, GILLMOR, CS, JIMENEZ, LF, GUEVARA-GARCIA，A，LEON， P (2004) CHLOROPLAST BIOGENESIS genes act cell and noncell autonomously in early chloroplast development. Plant Physiol 135: 471-482.

HAJDUKIEWICZ, PTJ, ALLISON, LA, MALIGA, P (1997) The two RNA polymerases encoded by the nuclear and the plastid compartments transcribe distinct groups of genes in tobacco plastids. EMBO J 16: 4041-4048.

HORMANN, F, KUCHLER, M, SVESHNIKOV, D, OPPERMANN, U, LI, Y, SOLL, J (2004) Tic32, an essential component in chloroplast biogenesis. J Biol Chem 279: 34756-34762.

KANAMARU, K, TANAKA, K (2004) Roles of chloroplast RNA polymerase sigma factors in chloroplast development and stress response in higher plants. Biosci Biotechnol Biochem 68: 2215-2223.

KUBIS, S, PATEL, R, COMBE, J, BEDARD, J, KOVACHEVA, S, LILLEY, K, et al. (2004) Functional specialization amongst the Arabidopsis Toc159 family of chloroplast protein import receptors. Plant Cell 16: 2059-2077.

LARKIN, RM, ALONSO, JM, ECKER, JR, CHORY, J (2003) GUN4, a regulator of chlorophyll synthesis and intracellular signaling. Science 299: 902-906.

LEON, P, ARROYO, A, MACKENZIE, S (1998) Nuclear Control of Plastid and Mitochondrial Development in Higher Plants. Annu Rev Plant Physiol Plant Mol Biol 49: 453-480

LOPEZ-JUEZ, E (2007) Plastid biogenesis, between light and shadows. J Exp Bot 58: 11-26.

LOPEZ-JUEZ, E, PYKE, KA (2005) Plastids unleashed: their development and their integration in plant development. Int J Dev Biol 49: 557-577.
MALIGA, P (1998) Two plastid RNA polymerases of higher plants: an evolving story. Trends in Plant Science 3: 4-6.

MANDEL, MA, FELDMANN, KA, HERRERAESTRELLA, L, ROCHA-SOSA, M, LEON, P (1996) CLA1, a novel gene required for chloroplast development, is highly conserved in evolution. Plant $\mathrm{J}$ 9: 649-658.

MOCHIZUKI, N, BRUSSLAN, JA, LARKIN, R, NAGATANI, A, CHORY, J (2001) Arabidopsis genomes uncoupled 5 (GUN5) mutant reveals the involvement of $\mathrm{Mg}$-chelatase $\mathrm{H}$ subunit in plastid-tonucleus signal transduction. Proc Natl Acad Sci U S A 98: 2053-2058

NOTT, A, JUNG, HS, KOUSSEVITZKY, S, CHORY, J (2006) Plastid-to-nucleus retrograde signaling. Annu Rev Plant Biol 57: 739-759.

PFALZ, J, LIERE, K, KANDLBINDER, A, DIETZ, KJ, OELMULLER, R (2006) pTAC2, -6 , and -12 are components of the transcriptionally active plastid chromosome that are required for plastid gene expression. Plant Cell 18: 176-197.

PYKE, KA (1999) Plastid division and development. Plant Cell 11: 549-556.

PYKE, KA, PAGE, AM (1998) Plastid ontogeny during petal development in Arabidopsis. Plant Physiol 116: 797-803.

ROLLETSCHEK, H, WEBER, H, BORISJUK, L (2003) Energy status and its control on embryogenesis of legumes. Embryo photosynthesis contributes to oxygen supply and is coupled to biosynthetic fluxes. Plant Physiol 132: 1196-1206.

ROSEN, E, CHEN, R, MASSON, PH (1999) Root gravitropism: a complex response to a simple stimulus? Trends Plant Sci 4: 407-412.

SAETHER, N, IVERSEN, TH (1991) Gravitropism and starch statoliths in an Arabidopsis mutant. Planta 184: 491-497.

SANTIS-MACIOSSEK, GD, KOFER, W, BOCK, A, SCHOCH, S, MAIER, RM, WANNER, G, et al. (1999) Targeted disruption of the plastid RNA polymerase genes rpoA, B and C1: molecular biology, biochemistry and ultrastructure. The Plant Journal 18: 477-489.

SCHERES, B, WOLKENFELT, H, WILLEMSEN, V, TERLOUW, M, LAWSON, E, DEAN, C, et al. (1994) Embryonic origin of the Arabidopsis primary root and root meristem initials. Development 120: 2475-2487.

SOMANCHI, A, MAYFIELD, SP (1999) Nuclearchloroplast signalling. Curr Opin Plant Biol 2: 404409 .

SPENCER, MWB, CASSON, SA, LINDSEY, K (2007) Transcriptional Profiling of the Arabidopsis Embryo. Plant Physiol 143: 924-940.

SUNDBERG, E, SLAGTER, JG, FRIDBORG, I, CLEARY SP, ROBINSON, C, COUPLAND, G (1997) ALBIN03, an Arabidopsis Nuclear Gene Essential for Chloroplast Differentiation, Encodes a Chloroplast Protein That Shows Homology to Proteins Present in Bacterial Membranes and Yeast Mitochondria. Plant Cell 9: 717 730 .

TZAFRIR, I, PENA-MURALLA, R, DICKERMAN, A, BERG, M, ROGERS, R, HUTCHENS, S, et al. (2004) Identification of genes required for embryo development in Arabidopsis. Plant Physiol 135: 12061220 .

UWER, U, WILLMITZER, L, ALTMANN, T (1998) Inactivation of a glycyl-tRNA synthetase leads to an arrest in plant embryo development. Plant Cell 10: 1277-1294. 
VAN DEN BERG, C, WILLEMSEN, V, HENDRIKS, G, WEISBEEK, P, SCHERES, B (1997) Short-range control of cell differentiation in the Arabidopsis root meristem. Nature 390: 287-289.

WEIJERS, D, SCHLERETH, A, EHRISMANN, JS, SCHWANK, G, KIENTZ, M, JURGENS, G (2006) Auxin triggers transient local signaling for cell specification in Arabidopsis embryogenesis. Dev Cell 10: 265-270.

WILDWATER, M, CAMPILHO, A, PEREZ-PEREZ, JM, HEIDSTRA, R, BLILOU, I, KORTHOUT, H, et al. (2005) The RETINOBLASTOMA-RELATED gene regulates stem cell maintenance in Arabidopsis roots. Cell 123: 1337-1349.

WOODSON, JD, CHORY, J (2008) Coordination of gene expression between organellar and nuclear genomes. Nat Rev Genet 9: 383-395.
XU, XM, MOLLER, SG (2004) AtNAP7 is a plastidic SufC-like ATP-binding cassette/ATPase essential for Arabidopsis embryogenesis. Proc Natl Acad Sci U S A 101: 9143-9148

YU, B, WAKAO, S, FAN, J, BENNING, C (2004) Loss of plastidic lysophosphatidic acid acyltransferase causes embryo-lethality in Arabidopsis. Plant Cell Physiol 45: 503-510.

ZHAO, CM, CHEN, D, LINTUNEN, M, PANULA, P, HAKANSON, R (1999) Effects of reserpine on ECLcell ultrastructure and histamine compartmentalization in the rat stomach. Cell Tissue Res 295: 131-140.

ZHAO, L, SACK, FD (1999) Ultrastructure of stomatal development in Arabidopsis (Brassicaceae) leaves. Am J Bot 86: 929. 
